\title{
Brucine Diol-Catalyzed Enantioselective Morita-Baylis-Hillman Reaction in the Presence of Brucine N-Oxide
}

\author{
Venkatachalam Angamuthu ${ }^{1} \mathbb{D}$, Chia-Hung Lee ${ }^{2, *}$ and Dar-Fu Tai ${ }^{1, *}$ \\ 1 Department of Chemistry, National Dong-Hwa University, Hualien 974003, Taiwan; \\ venkatachalam_83@yahoo.co.in \\ 2 Department of Life Science, National Dong-Hwa University, Hualien 974003, Taiwan \\ * Correspondence: chlee016@gms.ndhu.edu.tw (C.-H.L.); dftai@gms.ndhu.edu.tw (D.-F.T.); \\ Tel.: +886-3-890-3677 (C.-H.L.); +886-3-890-3579 (D.-F.T.); Fax: +886-3-890-0163 (C.-H.L.); \\ +886-3-890-0162 (D.-F.T.)
}

Citation: Angamuthu, V.; Lee, C.-H.; Tai, D.-F. Brucine Diol-Catalyzed Enantioselective Morita-BaylisHillman Reaction in the Presence of Brucine N-Oxide. Catalysts 2021, 11, 237. https://doi.org/10.3390/ catal11020237

Academic Editor: Takeshi Okhuma

Received: 23 January 2021

Accepted: 5 February 2021

Published: 10 February 2021

Publisher's Note: MDPI stays neutral with regard to jurisdictional claims in published maps and institutional affiliations.

Copyright: (c) 2021 by the authors. Licensee MDPI, Basel, Switzerland. This article is an open access article distributed under the terms and conditions of the Creative Commons Attribution (CC BY) license (https:// creativecommons.org/licenses/by/ $4.0 /)$.

\begin{abstract}
Brucine diol (BD) catalyzed asymmetric Morita-Baylis-Hillman (MBH) reaction is observed for the first time. Brucine N-oxide (BNO) was found to not have an effective chiral catalyst. Faster reaction rate was obtained using unsaturated ester or aromatic aldehydes in the presence of BNO. 4-Nitrobenzaldehyde and $\alpha, \beta$-unsaturated ketone/ester were converted to the MBH adduct in moderate yields (up to $74 \%$ ) with $70 \%$ ee value by this catalytic system. The mechanism of BD catalysis is probably initiated by conjugating the vicinal diol of $\mathrm{BD}$ to the carbonyl group of the aromatic aldehyde through hydrogen bonding. The tertiary amine of BD acts as a nucleophile to activate vinyl ketone for coupling with the carbonyl of aldehyde through an intramolecular carbonylated reaction. Finally, the breakdown of the complex caused the formation of the $\mathrm{MBH}$ adduct (a benzyl-allyl alcohol). The chirality of the benzyl-allyl alcohol is likely affected by the interaction of the bulky asymmetric plane of BD.
\end{abstract}

Keywords: dihydroxy brucine; Morita-Baylis-Hillman reaction; brucine-N-oxide

\section{Introduction}

Chiral amines are continuing to play a pivotal role as a catalyst in asymmetric synthesis [1]. The asymmetric induction of chiral secondary amines originates from the $\alpha$-carbon chiral center to the nitrogen in the structure of the amine molecule [2-5]. In the case of chiral tertiary amines, the asymmetric induction by these catalysts is primarily derived from the nitrogen chiral center and a secondary anchoring group is often necessary. These chiral tertiary amines are usually classified as nucleophilic catalysts [6-9]. A number of tertiary amine $\mathrm{N}$-oxides [10] have been developed and utilized for various asymmetric reactions. They are mainly cyclic aliphatic N-oxides [11] and pyridine N-oxides [12-15], acting as a ligand to coordinate with low valent transition metals [16] for metal-catalyzed reactions. Chiral natural products with bulky shapes and inflexibility $[7,17]$ are used, such as brucine derivatives (1).

As shown in Scheme 1, Oh et al., used brucine $\mathrm{N}$-oxide (BNO) as a chiral ligand for metal catalyzed asymmetric epoxidation [18]. They also reported the use of BNO $1 \mathrm{a}$ or $1 \mathrm{~b}$ to catalyze asymmetric Morita-Baylis-Hillman (MBH) reaction, but the chiral induction was due to the presence of (L)/(D)-proline [19,20]. Moreover, brucine diol (BD) was found to incorporate with copper (I) salt to catalyze an asymmetric Henry reaction [21]. Integration of BD 2 with zinc was able to perform 1,3-dipolar cycloaddition [22-24] (Scheme 1).

The classical $\mathrm{MBH}$ reaction can be broadly defined as the $\mathrm{C}-\mathrm{C}$ bond forming reaction between the $\alpha$-position of an activated alkene and aldehyde to provide $\alpha$-methylene- $\beta$ hydroxycarbonyl compound. The $\mathrm{MBH}$ reaction probably involves the mildest reaction condition and has been comprehensively reviewed [6,23,25-29]. 


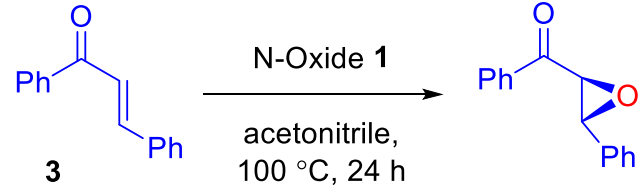

$4(\alpha S, \beta R)$

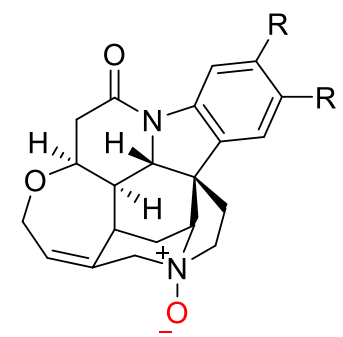

BNO 1a: $\mathrm{R}=\mathrm{H}$

$1 \mathrm{~b}: \mathrm{R}=\mathrm{OMe}$

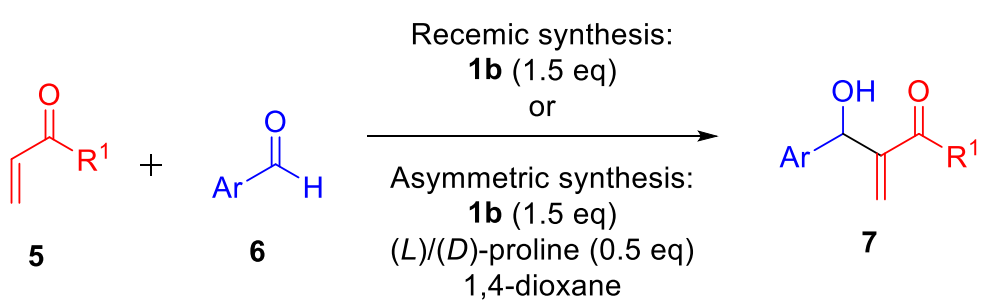
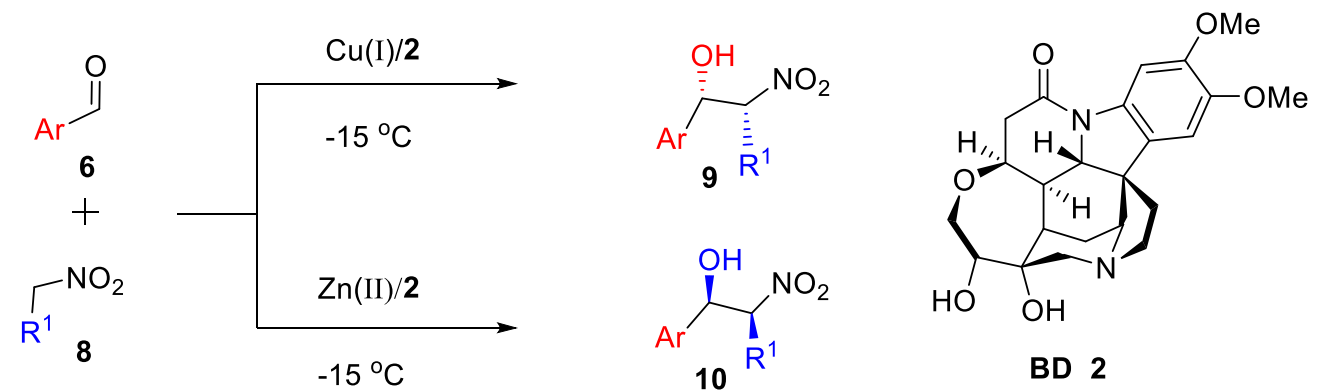

Scheme 1. Brucine derivatives in asymmetric synthesis.

The mechanism of the $\mathrm{MBH}$ reaction is complicated. There are several types of mechanism proposed in the literature. Type I is consistent with a nucleophilic 1,4 addition to the $\alpha, \beta$-unsaturated compound by the catalyst (a tertiary amine or $N$-oxide, phosphines) to form a Michael-addition species, which further reacts with the aromatic aldehyde to form a ternary complex [28]. Decomposition of the ternary complex results in the $\mathrm{MBH}$ adduct and regenerates the catalyst.

Type II mechanism proceeds the same route as type I at the beginning to form the ternary complex, according to Aggarwal [30,31] and McQuade [32,33]. The addition of the fourth element (a protic polar solvent or another aldehyde) produces a 4-component species. Finally, this 4-component species decomposes to result in the $\mathrm{MBH}$ adduct and regenerates the catalyst.

The type III mechanism is proposed by $\mathrm{Oh}$ as a dual catalytic system [18]. It proceeds the same route as Type I at the earlier stage, $N$-oxide reacts with an $\alpha, \beta$-unsaturated carbonyl compound to form a Michael-addition species and then the ternary complex. Meanwhile, another aldehyde reacts with an L-proline to create a chiral iminium ion, which is attacked by the Michael-addition species to form a 3 plus 2 complexes. After decomposition, the nucleophile and hydrolysis of imine produce a chiral $\mathrm{MBH}$ adduct. The rate of this dual system would be low without L-proline, which also induces the chirality of $\mathrm{MBH}$ adduct.

The type IV mechanism is based on the catalyst attached with a hydroxyl group (a tertiary aminol) to enhance the rate of the $\mathrm{MBH}$ reaction. Many catalysts with a hydroxyl amine functional group demonstrate rate enhancement. As shown in Scheme 2, both Marko [34] and Barrett [35] proposed a similar concept to complex the substrates in which 
the Michael-addition species is bonded to the aldehyde with the help of the hydroxyl group. Formation of the hydrogen bonded intermediate is considered the rate determining step.

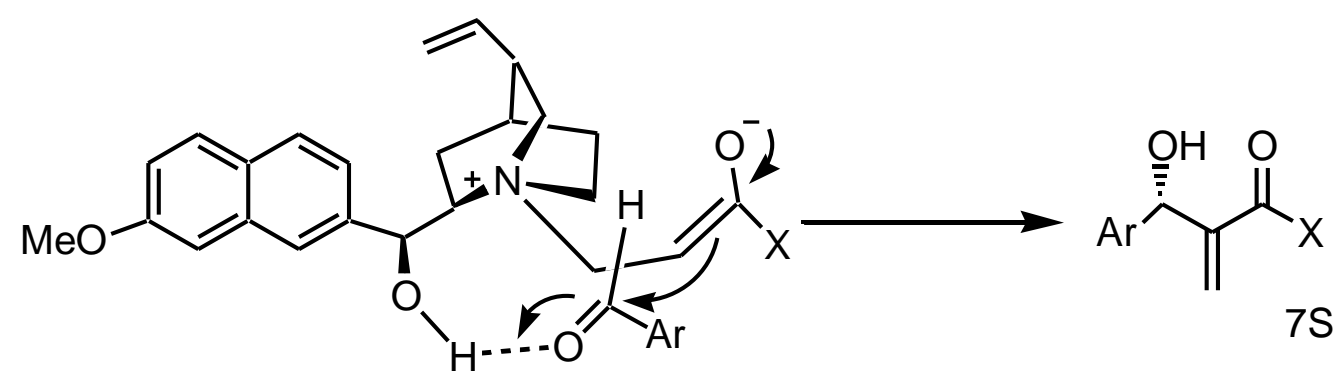

Marko's intermediate

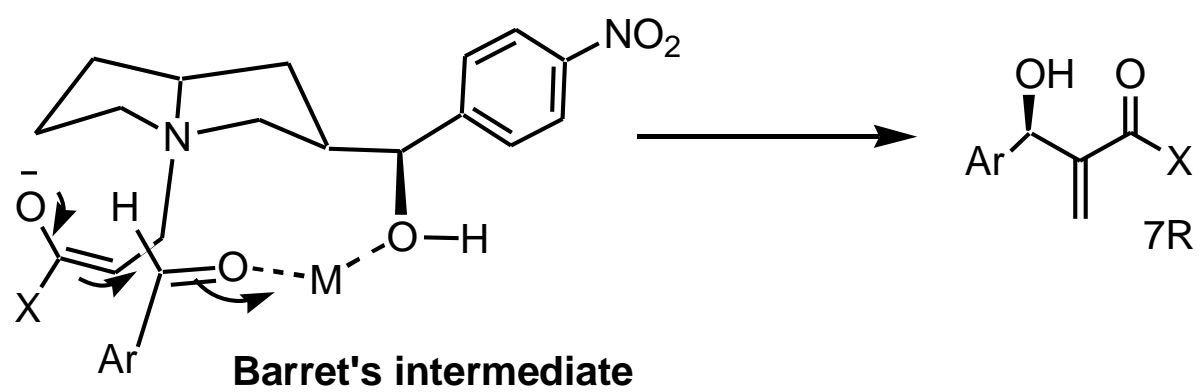

Scheme 2. Proposed type IV mechanism: a tertiary aminol catalyzed Morita-Baylis-Hillman $(\mathrm{MBH})$ reaction.

$\mathrm{BD}$ has not been studied as a catalyst for asymmetric $\mathrm{MBH}$ reaction so far. However, it possesses a vicinal diol which can act as carbonyl activator through hydrogen bindings. In addition to its unique aminol structure, we anticipated that BD could interact with various reactants to act as a nucleophilic catalyst for asymmetric $\mathrm{MBH}$ reaction. Based on the proposed type IV mechanism in Scheme 2, catalytic activity of BD is expected. Although BNO [18,19] can't function asymmetrically alone, aliphatic $N$-oxides $[11,36]$ have been known as a good nucleophile. $N$-oxides are easy to synthesize and preserve. Therefore, $\mathrm{BNO}$ was also considered as a co-catalyst with BD for asymmetric reaction. Herein, we report the investigation of catalytic ability of $\mathrm{BD}$ alone and $\mathrm{BD}$ with $\mathrm{BNO}$ as a co-catalyst in asymmetric $\mathrm{MBH}$ reaction.

\section{Results and Discussion}

The BNO 1b [37] and BD 2 [20] was synthesized as previously reported. Initially, 4-nitrobenzaldehyde and methyl vinyl ketone (MVK) were used as substrates in an $\mathrm{MBH}$ reaction to study the catalytic efficiency of BD. As shown in Table 1, variation in nonpolar solvent with $5 \mathrm{~mol} \%$ of BD led to low yields and poor ee values (entries 1-4). Increasing the catalytic ratio of $\mathrm{BD}$ to $10 \mathrm{~mol} \%$ in polar solvent (ethanol or dioxane) gave moderate yields and ee values (entries 5,6). As the catalytic load was increased to $20 \mathrm{~mol} \%$ in acetonitrile (entry 7$)$, the yield (61\%) and ee value (59\%) also increased. The reaction time was monitored for 6 days. When BD increased to $30 \mathrm{~mol} \%$, the yield also increased to $69 \%$, but the ee value reduced to $53 \%$ (entry 8 ). The optimized condition for BD is thus settled to $20 \mathrm{~mol} \% \mathrm{BD}, 2$ equivalents of MVK in acetonitrile for 6 days at room temperature (entry 7). BNO (10 20 $\mathrm{mol} \%$ ) alone in acetonitrile resulted in $>5 \%$ of yield (entries 9,10 ). 
Table 1. Asymmetric MBH reaction with catalyst brucine N-oxide (BNO) and brucine diol (BD) [a].<smiles>C=CC(C)=O</smiles>

$6 a$

5

$7 a$

\begin{tabular}{|c|c|c|c|c|c|c|c|}
\hline Entry & Catalyst & Mol\% & $\begin{array}{c}5 \\
\text { [Equiv] }\end{array}$ & $\begin{array}{l}\text { Solvent }^{[b]} \\
{[\text { Vol] }}\end{array}$ & Time [days] & $\begin{array}{c}\text { Yield }^{[c]} \\
{[\%]}\end{array}$ & $\begin{array}{c}\mathrm{Ee}^{[\mathrm{d}]} \\
{[\%]}\end{array}$ \\
\hline 1 & $\mathrm{BD}$ & 5 & 2 & DCM & 6 & 22 & 23 \\
\hline 2 & $\mathrm{BD}$ & 5 & 2 & DCE & 6 & 21 & 27 \\
\hline 3 & $\mathrm{BD}$ & 5 & 2 & $\mathrm{iPrOH}$ & 6 & 31 & 23 \\
\hline 3 & $\mathrm{BD}$ & 5 & 2 & Toluene & 6 & 23 & 27 \\
\hline 4 & $\mathrm{BD}$ & 10 & 2 & Ethanol & 6 & 30 & 34 \\
\hline 5 & $\mathrm{BD}$ & 10 & 2 & 1,4-dioxane & 6 & 43 & 44 \\
\hline 6 & $\mathrm{BD}$ & 20 & 2 & Acetonitrile & 6 & 61 & 59 \\
\hline 7 & $\mathrm{BD}$ & 30 & 2 & Acetonitrile & 6 & 69 & 53 \\
\hline 8 & $\mathrm{BNO}$ & 10 & 10 & Acetonitrile & 10 & $>5$ & 10 \\
\hline 9 & $\mathrm{BNO}$ & 20 & 10 & Acetonitrile & 10 & $>5$ & 19 \\
\hline
\end{tabular}

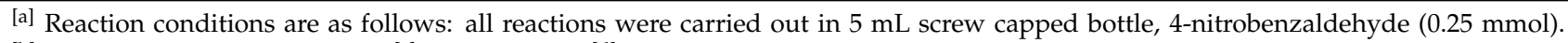

${ }^{[b]}$ Solvents used without drying. ${ }^{[c]}$ Isolated yield. ${ }^{[d]}$ Determined by chiral High performance liquid chromatography (HPLC).

This is the first report about using BD as a catalyst in an asymmetric $\mathrm{MBH}$ reaction. Stereochemical outcome can be explained in the proposed mechanism as shown in Scheme 3. BD formed the ternary complex (transition state A) with diol by Michael addition to the $\alpha, \beta$-unsaturated carbonyl 5 and hydrogen bonded with the carbonyl groups of aromatic aldehyde $\mathbf{6 a}$. The coupling between enone and aldehyde induced the formation of the chiral $\mathrm{MBH}$ adduct $7 \boldsymbol{R}$. Due to the bulky structure of BD, the other side attack is less favored.

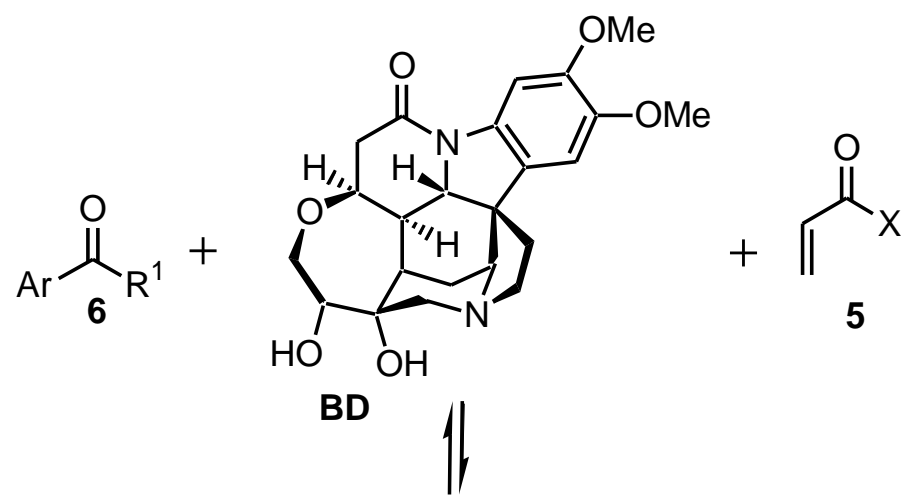

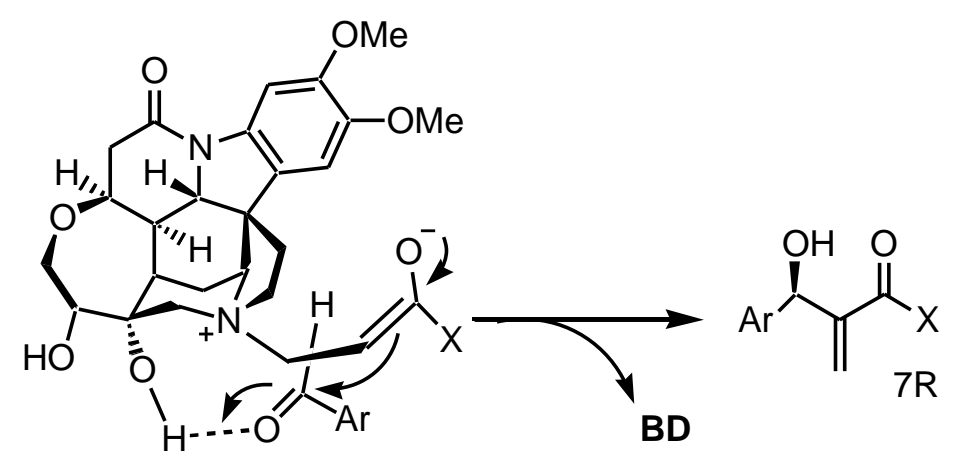

Transition state $\mathbf{A}$

Scheme 3. Proposed mechanism of BD catalyzed $\mathrm{MBH}$ reaction. 
To speed up the reaction rate, cooperation of $\mathrm{BD}$ with a co-catalyst $\mathrm{BNO}$ was evaluated. As shown in Scheme 4, a co-catalytic mechanism was proposed. First, this dual catalytic system could be initiated by conjugating the vicinal diol of BD to the carbonyl group of the aromatic aldehyde and vinyl ketone through hydrogen bonding, respectively. Second, the $\mathrm{N}$-oxide of BNO acts as a nucleophile to activate vinyl ketone for coupling with the carbonyl of aldehyde through an intramolecular carbonyl ene reaction. Finally, the breakdown of the dual catalytic system caused the formation of the $\mathrm{MBH}$ adduct. The interaction of the asymmetric plane of $\mathrm{BD}$ with $\mathrm{BNO}$ could promote the chirality of the product.

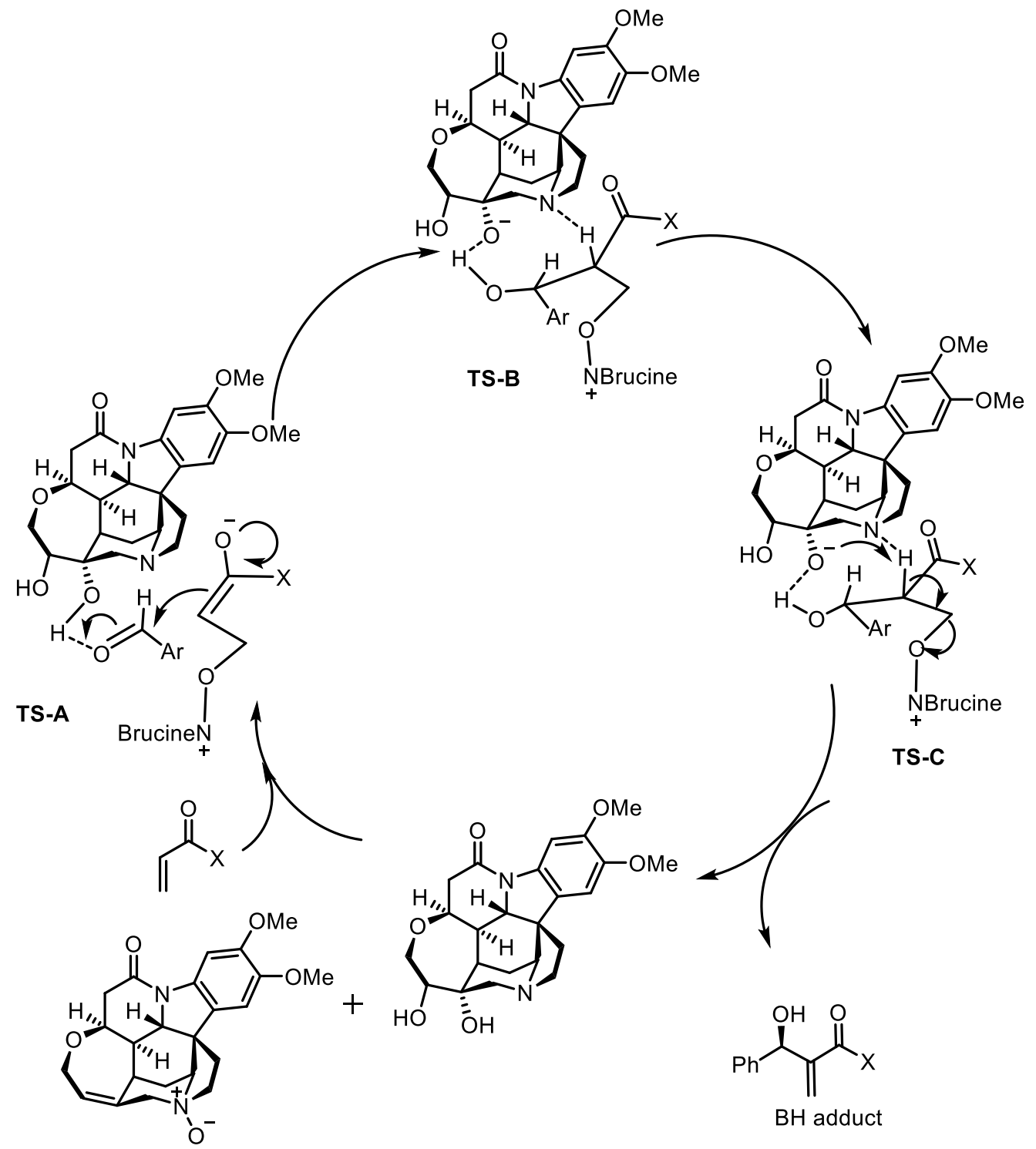

Scheme 4. Proposed catalytic cycle for BD catalyzed MBH reaction with BNO.

Unfortunately, the proposed mechanism in Scheme 4 was not validated by the experimental data. The co-catalytic system was evaluated and is shown in Table 2. Compared to $\mathrm{BD}$ alone (Table 1, entry 8 ), adding $20 \mathrm{~mol} \%$ of $\mathrm{BNO}$ had no effect on ee value and yield (Table 2, entry 1 ). As the amount of $\mathrm{BD} / \mathrm{BNO}$ were further increased $(25 / 50 \%)$, an improvement to $67 \%$ yield was observed but the ee value reduced to $54 \%$ (Table 2, entry 2). 
Table 2. Asymmetric MBH reaction with duel catalytic system ${ }^{[a]}$.

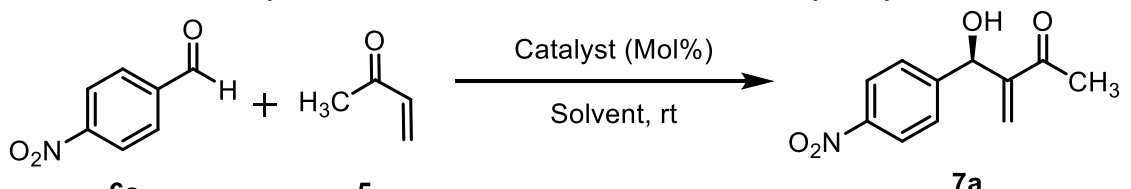

6a

5

\begin{tabular}{|c|c|c|c|c|c|c|}
\hline Entry & $\begin{array}{c}\text { Cat.1 } \\
\text { [Mol \%] }\end{array}$ & $\begin{array}{c}5 \\
\text { [Equiv] }\end{array}$ & $\begin{array}{c}\text { Cat. } 2 \\
\text { [Mol \%] }\end{array}$ & Time [days] & $\begin{array}{l}\text { Yield }^{[b]} \\
{[\%]}\end{array}$ & $\operatorname{Ee}^{[c]}[\%]$ \\
\hline 1 & $\mathrm{BD}[20]$ & 2 & BNO [20] & 6 & 60 & 59 \\
\hline 2 & $\mathrm{BD}[25]$ & 2 & BNO [50] & 6 & 67 & 54 \\
\hline 3 & $\mathrm{BD}$ [25] & 4 & $\mathrm{BNO}[60]$ & 4 & 69 & 56 \\
\hline 4 & $\mathrm{BD}[25]$ & 4 & $\mathrm{BNO}[70]$ & 4 & 71 & 54 \\
\hline 5 & $\mathrm{BD}$ [25] & 4 & $\mathrm{BNO}[80]$ & 4 & 72 & 55 \\
\hline 6 & $\mathrm{BD}$ [25] & 4 & BNO [100] & 4 & 74 & 57 \\
\hline 7 & BD [20] & 4 & BNO [100] & 4 & 74 & 70 \\
\hline 8 & $\mathrm{BD}[20]$ & 4 & PNO [100] & 8 & 17 & - \\
\hline
\end{tabular}

[a] Reaction condition: all reactions were carried out in $5 \mathrm{~mL}$ screw capped bottle, 4-nitrobenzaldehyde $(0.25 \mathrm{mmol}) .{ }^{\text {[b] }}$ Isolated yield.

[c] Determined by chiral HPLC.

Interestingly, the yield increased up to $74 \%$ when increasing the $\mathrm{mol} \%$ of $\mathrm{BNO}$, but there was no effect on the ee values (entries 3-6). Finally, with $20 \mathrm{~mol} \%$ of BD [21] and $100 \mathrm{~mol} \%$ of BNO in acetonitrile using 4 equivalents of MVK, $74 \%$ yield and $70 \%$ ee value (entry 7) was reached. The activity was also compared with catalyst mixtures of other $\mathrm{N}$-oxide, such as pyridine $\mathrm{N}$-oxide (PNO) and morpholine $\mathrm{N}$-oxide with $\mathrm{BD}$. These catalytic mixtures gave only $17 \%$ of yield and the duration was too long (entry 8 ). Therefore, $\mathrm{N}$ oxides are clearly less involved in the activation of $\alpha, \beta$-unsaturated aldehydes or ketones. This clearly reveals that the BNO is not responsible for either acylation of the rate or chiral induction. Cooperative effect between BD and BNO was not observed as Scheme 4. BNO simply increased the chiral concentration in the solution to promote the yield and ee value.

Substrate scope was evaluated with this combination by changing the Michael acceptors and substituted aromatic aldehyde as shown in Table 3. The co-catalytic system provided moderate to good yields (up to $74 \%$ ) and ee values (up to $78 \%$ ) using optimal reaction condition. Generally, acyclic esters are less reactive but in this case hydroxyl substituted acrylate (3-hydroxyphenyl acrylate) provided $\mathrm{b}$ in moderated yield and ee value (Table 3, entry 2). Reaction of cyclohexenone with 4-nitrobenzaldehyde provided 7c in $78 \%$ of ee value and $54 \%$ of yield. A simple phenyl aldehyde gave $7 \mathrm{~d}$ in $61 \%$ of yield and $55 \%$ of ee value (entry 4 ), which is relatively less than 4-nitro-substituted aromatic aldehyde with MVK (Table 3, entry 1). The results showed the cyclic enone could be better candidate for the Michael acceptors which provided $78 \%$ of ee value (entry 3 ). This is probably due to the effective binding of cyclic enone with BD [38]. 


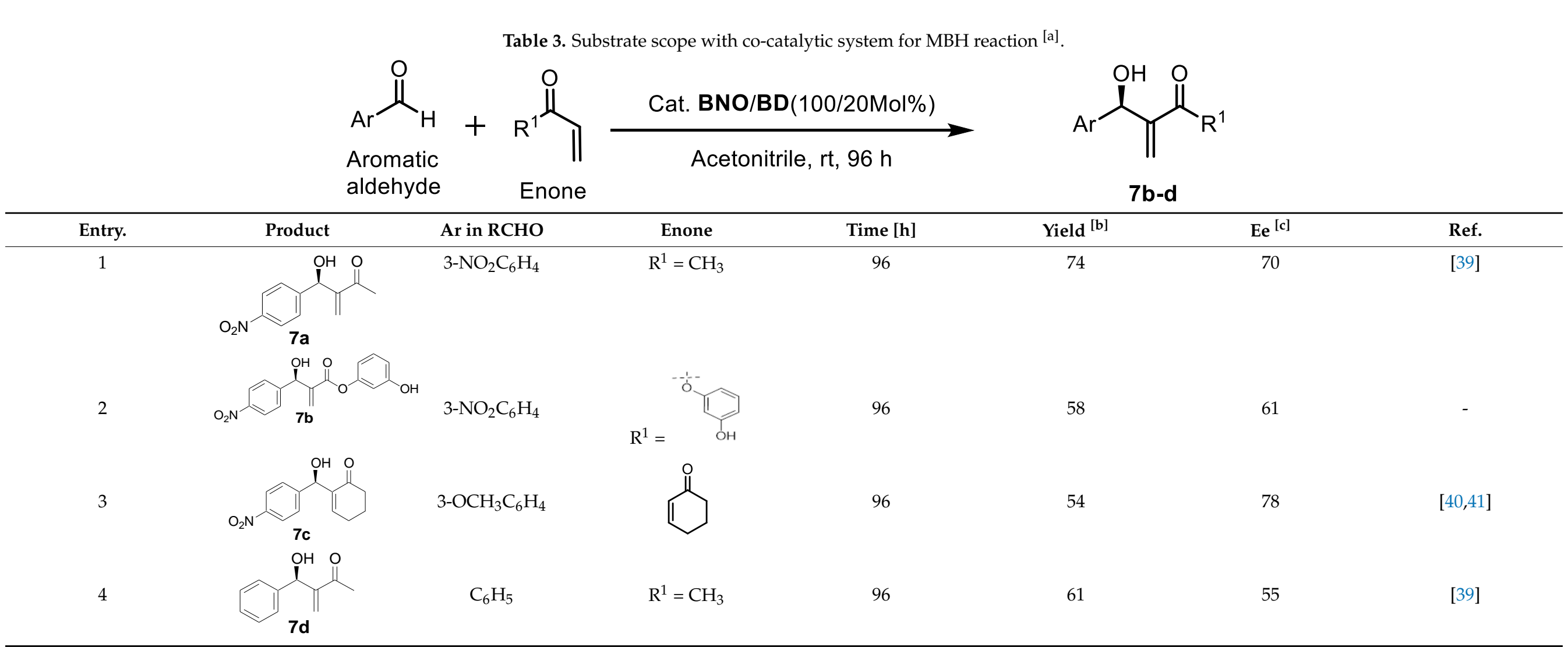

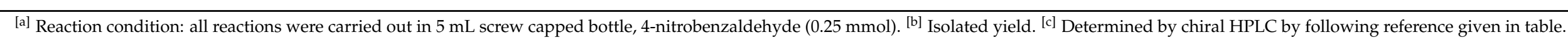


However, we were pleased to find that $\mathrm{BD}$ combined with $\mathrm{BNO}$ in view of increasing the chiral concentration in the solution to give the allyl alcohol 7a-d in 4 days and provided moderate yield and ee value. This is important because there is no report about using BD as a catalyst in asymmetric $\mathrm{MBH}$ reactions. BD was reported previously only for asymmetric Henry reaction with copper (I) salt [20]. The absolute configuration of the products was assigned as R0-based on a correlation with known compounds [39,41,42].

\section{Materials and Methods}

\subsection{General Information}

All solvents were commercially available grade unless otherwise stated. The aldehydes, MVK and 3-hydroxylphenyl acrylate were used as purchased. The products were purified by neutral column chromatography on 70-230 or 230-400 mesh silica gels. Spectra obtained were ${ }^{1} \mathrm{H}$ NMR and ${ }^{13} \mathrm{C}$ NMR from 400 and $100.6 \mathrm{MHz}$ NMR spectrometer, respectively (Supplementary Materials). Chemical shifts $(\delta)$ are reported in parts per million (ppm) from residual solvent resonance as the internal standard. Coupling constants are reported in Hertz $(\mathrm{Hz})$ and the multiplicities are indicated as br = broad, $\mathrm{s}=$ singlet, $\mathrm{d}=$ doublet, $\mathrm{dd}=$ doublet of doublet, $\mathrm{t}=$ triplet, $\mathrm{m}=$ multiple. Enantiomeric excesses were determined using chiral high performance liquid chromatography. IR spectra were obtained from a Jasco FT/IR-480 Plus instrument using KBr disks. Elemental analysis (EA) was obtained from ThermoQuest (Flash 1112EA, ITALY).

\subsection{General Procedure 1: MBH Reaction with Single Catalytic Processes}

Catalysts BNO and BD $(0.25 \mathrm{mmol})$ were used. In a screw caped vial, a single catalyst ( $0.25 \mathrm{mmol})$ in $0.2 \mathrm{~mL}$ of given solvent, 4-nitrobenzaldehyde and MVK (given equivalent) were mixed at room temperature. The resulting solution was stirred at room temperature for 6-8 days. The reaction was monitored by TLC. After completion, the mixture was diluted with ethyl acetate $(1 \mathrm{~mL})$ and concentrated under reduced pressure. The resultant crude was purified by column chromatography on silica gel (hexanes/EtOAc, 90:10) to provide allylic alcohol 7a.

\subsection{General Procedure 2: $\mathrm{MBH}$ Reaction with BD and BNO Co-Catalytic Processes}

Catalytic mixtures BD/BNO (0.25 mmol (total molar ratio)) were dispersed in $0.2 \mathrm{~mL}$ of given solvent. The semi-homogeneous solution was stirred for $10 \mathrm{~min}$, the corresponding aldehyde ( $0.25 \mathrm{mmol}$ ) and methyl vinyl ketone (given equivalent) or acrylate (4 equiv) was added. The resulting solution was stirred at room temperature. Completion of the reaction was monitored by TLC. After the indicated reaction time, ethyl acetate ( $1 \mathrm{~mL})$ was added, and the extracts were easily separated by applying a separating funnel. The extracts were combined and concentrated. Further purified by column chromatography on silica gel (hexanes/EtOAc, 90:10) provided corresponding allylic alcohol.

\subsection{3-Hydroxyphenyl 2-(hydroxy(4-nitrophenyl)methyl)acrylate (7b)}

Brownish oil: ${ }^{1} \mathrm{H}$ NMR $\left(400 \mathrm{MHz}, \mathrm{CDCl}_{3}\right) \delta 7.49(\mathrm{~d}, J=8.0 \mathrm{~Hz}, 2 \mathrm{H}), 7.29(\mathrm{~d}, J=8.0 \mathrm{~Hz}$, $2 \mathrm{H}), 7.18(\mathrm{t}, J=8.0 \mathrm{~Hz}, 1 \mathrm{H}), 6.60-6.55(\mathrm{~m}, 3 \mathrm{H}), 6.47(\mathrm{~s}, 1 \mathrm{H}), 6.05(\mathrm{~s}, 1 \mathrm{H}), 5.62(\mathrm{~s}, 1 \mathrm{H}):{ }^{13} \mathrm{C}$ NMR $\left(100 \mathrm{MHz}_{2} \mathrm{CDCl}_{3}\right) \delta 164.7,156.6,151.1,141.3,139.9,131.7,130.2,128.2,122.1,113.5$, $113.4,109.1,72.5$.

\section{Conclusions}

We studied in detail the comparative catalytic efficiency by single and combined catalytic systems using $\mathrm{BNO}$ and $\mathrm{BD}$ in an $\mathrm{MBH}$ reaction. In a process with a single catalyst, $\mathrm{BD}$ (20 mol\%) gave respective $\mathrm{MBH}$ adduct of $7 \mathrm{a}$ in moderate yield and ee value (59\%). In a co-catalytic system, the mixture of $\mathrm{BD} / \mathrm{BNO}$ provided better results. $\mathrm{MBH}$ adducts were achieved up to $74 \%$ yield and $78 \%$ ee value. In this asymmetric reaction, chiral induction was mainly due to tertaryamino-1,2-diol of BD which activated the carbonyl group through hydrogen bonding. The BD/BNO cooperative catalytic system provides rate enhancement 
which may be due to increasing the chiral concentration in the solution by BNO in the mixture.

Supplementary Materials: The following are available online at https:/ /www.mdpi.com/2073-4 344/11/2/237/s1, Figure S1: ${ }^{1} \mathrm{H}$ NMR of BD. Figure S2: ${ }^{13} \mathrm{C}$ NMR of BD. Figure S3: LRMS of BD. Figure S1. ${ }^{1} \mathrm{H}$ NMR of BD. Figure S4: ${ }^{1} \mathrm{HNMR}$ of compound 7a. Figure S5: ${ }^{1} \mathrm{H}$ NMR of compound 7b. Figure S6: ${ }^{13} \mathrm{C}$ NMR of compound $7 \mathbf{b}$. Figure S7: HPLC of compound 7a (racemic). Figure S8: HPLC of compound 7a. Figure S9: HPLC of compound $\mathbf{7 b}$.

Author Contributions: V.A. and D.-F.T. designed the experiments and wrote the manuscript; D.-F.T. Supervised study; V.A. performed the experiments; V.A., D.-F.T., C.-H.L. contributed to scientific discussions. All authors have read and agreed to the published version of the manuscript.

Funding: This research was funded by Taiwan Ministry of Science and Technology grant number [NSC100-2622-M-259-001-CC2].

Data Availability Statement: Not applicable.

Acknowledgments: We thank Taiwan Ministry of Science and Technology for providing the financial support (NSC100-2622-M-259-001-CC2).

Conflicts of Interest: The authors declare no conflict of interest.

\section{References}

1. Albrecht Berkessel, H.G. Asymmetric Organocatalysis; Wiley-VCH: Weinheim, Germany, 2005.

2. List, B. The ying and yang of asymmetric aminocatalysis. Chem. Commun. 2006, 819-824. [CrossRef] [PubMed]

3. Macmillan, D.W.C. The advent and development of organocatalysis. Nature 2008, 455, 304-308. [CrossRef]

4. Yu, Y.W.T.; Xu, P. A New Approach for Supramolecular Iminium Catalysis. Acta Chim. Sin. 2014, 72, 845-848. [CrossRef]

5. Dalko, P.I.; Moisan, L. In the golden age of organocatalysis. Angew. Chem. Int. Ed. 2004, 43, 5138-5175. [CrossRef]

6. Masson, G.; Housseman, C.; Zhu, J. The enantioselective morita-baylis-hillman reaction and its aza counterpart. Angezw. Chem. Int. Ed. 2007, 46, 4614-4628. [CrossRef]

7. Marcelli, T.; Van Maarseveen, J.H.; Hiemstra, H. Cupreines and cupreidines: An emerging class of bifunctional cinchona organocatalysts. Angew. Chem. Int. Ed. 2006, 45, 7496-7504. [CrossRef] [PubMed]

8. Tian, S.-K.; Chen, Y.; Hang, J.; Tang, L.; McDaid, P.; Deng, L. Asymmetric organic catalysis with modified cinchona alkaloids. Accounts Chem. Res. 2004, 37, 621-631. [CrossRef] [PubMed]

9. France, S.; Guerin, D.J.; Miller, S.J.; Lectka, T. Nucleophilic chiral amines as catalysts in asymmetric synthesis. Chem. Rev. 2003, 103, 2985-3012. [CrossRef]

10. Albini, A. Synthetic utility of amine N-oxides. Synthesis 1993, 1993, 263-277. [CrossRef]

11. Yu, Z.; Liu, X.; Dong, Z.; Xie, M.; Feng, X. An N,N'-Dioxide/In(OTf)3 catalyst for the asymmetric hetero-diels-alder reaction between danishefsky's dienes and aldehydes: Application in the total synthesis of triketide. Angew. Chem. Int. Ed. 2008, 47, 1308-1311. [CrossRef] [PubMed]

12. Chelucci, G.; Murineddu, G.; Pinna, G.A. Chiral pyridine N-oxides: Useful ligands for asymmetric catalysis. Tetrahedron Asymmetry 2004, 15, 1373-1389. [CrossRef]

13. Malkov, A.V.; Bell, M.; Castelluzzo, F.; Kočovský, P. METHOX: A New pyridine N-oxide organocatalyst for the asymmetric allylation of aldehydes with allyltrichlorosilanes. Org. Lett. 2005, 7, 3219-3222. [CrossRef]

14. Bai, B.; Yang, J.; Zhang, G.; Mao, D. Application of N-oxides as organocatalysts in asymmetric reaction. Chin. J. Org. Chem. 2015, 35, 975-979. [CrossRef]

15. Xie, W.; Zheng, Y.; Zhao, S.; Yang, J.; Liu, Y.; Wu, P. Selective oxidation of pyridine to pyridine-N-oxide with hydrogen peroxide over Ti-MWW catalyst. Catal. Today 2010, 157, 114-118. [CrossRef]

16. Luh, T.-Y. Trimethylamine N-oxide-A versatile reagent for organometallic chemistry. Coord. Chem. Rev. 1984, 60, 255-276. [CrossRef]

17. Nakayama, Y.; Gotanda, T.; Ito, K. Asymmetric Morita-Baylis-Hillman reactions of 2-cyclohexen-1-one catalyzed by chiral biaryl-based bis(thiourea) organocatalysts. Tetrahedron Lett. 2011, 52, 6234-6237. [CrossRef]

18. Oh, K.; Li, J.-Y.; Ryu, J. Brucine N-oxide-catalyzed Morita-Baylis-Hillman reaction of vinyl ketones: A mechanistic implication of dual catalyst system with proline. Org. Biomol. Chem. 2010, 8, 3015-3024. [CrossRef]

19. Oh, K.; Li, J.-Y. A cooperative catalysis approach to the morita-baylis-hillman reaction of aryl vinyl ketones. Synthesis 2011, 2011, 1960-1967. [CrossRef]

20. Kim, H.Y.; Oh, K. Brucine-derived amino alcohol catalyzed asymmetric henry reaction: An orthogonal enantioselectivity approach. Org. Lett. 2009, 11, 5682-5685. [CrossRef] [PubMed]

21. Li, J.-Y.; Kim, H.Y.; Oh, K. Brucine diol-copper-catalyzed asymmetric synthesis of endo-pyrrolidines: The mechanistic dichotomy of imino esters. Org. Lett. 2015, 17, 1288-1291. [CrossRef] [PubMed] 
22. Li, J.-Y.; Kim, H.Y.; Oh, K. Enantiodivergent brucine diol-catalyzed 1,3-dipolar cycloaddition of azomethine ylides with $\alpha, \beta-$ unsaturated Ketones. Adv. Synth. Catal. 2016, 358, 984-993. [CrossRef]

23. Basavaiah, D.; Rao, A.J.; Satyanarayana, T. Recent advances in the baylis-hillman reaction and applications. Chem. Rev. 2003, 103, 811-892. [CrossRef] [PubMed]

24. Oh, K.; Kim, H.Y. Stereodivergent asymmetric reactions catalyzed by brucine diol. Synlett 2015, 26, 2067-2087. [CrossRef]

25. Wei, Y.; Shi, M. Recent advances in organocatalytic asymmetric morita-baylis-hillman/aza-morita-baylis-hillman reactions. Chem. Rev. 2013, 113, 6659-6690. [CrossRef]

26. Langer, P. New strategies for the development of an asymmetric version of the baylis-hillman reaction. Angew. Chem. Int. Ed. 2000, 39, 3049-3052. [CrossRef]

27. Declerck, V.; Martinez, J.; Lamaty, F. Aza-baylis-hillman reaction. Chem. Rev. 2009, 109, 1-48. [CrossRef]

28. Zhao, M.-X.; Wei, Y.; Shi, M. Chapter 1 morita-baylis-hillman reaction. In The Chemistry of the Morita-Baylis-Hillman Reaction; The Royal Society of Chemistry: Cambridge, UK, 2011; pp. 1-78.

29. Pellissier, H. Recent developments in the asymmetric organocatalytic Morita-Baylis-Hillman reaction. Tetrahedron 2017, 73, 2831-2861. [CrossRef]

30. Robiette, R.; Aggarwal, V.K.; Harvey, J.N. Mechanism of the morita-baylis-hillman reaction: A computational investigation. J. Am. Chem. Soc. 2007, 129, 15513-15525. [CrossRef] [PubMed]

31. Aggarwal, V.K.; Fulford, S.Y.; Lloyd-Jones, G.C. Reevaluation of the mechanism of the baylis-hillman reaction: Implications for asymmetric catalysis. Angew. Chem. Int. Ed. 2005, 44, 1706-1708. [CrossRef]

32. Price, K.E.; Broadwater, S.J.; Jung, H.M.; McQuade, D.T. Baylis-hillman mechanism: A new interpretation in aprotic solvents. Org. Lett. 2005, 7, 147-150. [CrossRef] [PubMed]

33. Price, K.E.; Broadwater, S.J.; Walker, A.B.J.; McQuade, D.T. A new interpretation of the baylis-hillman mechanism. J. Org. Chem. 2005, 70, 3980-3987. [CrossRef] [PubMed]

34. Markó, I.E.; Giles, P.R.; Hindley, N.J. Catalytic enantioselective Baylis-Hillman reactions. Correlation between pressure and enantiomeric excess. Tetrahedron 1997, 53, 1015-1024. [CrossRef]

35. Barrett, A.G.; Cook, A.S.; Kamimura, A. Asymmetric baylis-hillman reactions: Catalysis using a chiral pyrrolizidine base. Chem. Commun. 1998, 22, 2533-2534. [CrossRef]

36. Lin, Y.-S.; Liu, C.-W.; Tsai, T.Y.R. 1-Methylimidazole 3-N-Oxide as a New Promoter for the Morita-Baylis-Hillman Reaction. Cheminform 2005, 36, 1859-1861. [CrossRef]

37. Oh, K.; Ryu, J. Chiral tertiary amine N-oxides in asymmetric epoxidation of $\alpha$, $\beta$-unsaturated ketones. Tetrahedron Lett. 2008, 49, 1935-1938. [CrossRef]

38. Angamuthu, V.; Tai, D.-F. Chiral amine and macrocycle fabricated magnetic nanoparticle asymmetrically catalyzed direct aldol reaction. Sustain. Chem. Pharm. 2019, 13, 100152. [CrossRef]

39. Yuan, K.; Zhang, L.; Song, H.-L.; Hu, Y.; Wu, X. Chiral phosphinothiourea organocatalyst in the enantioselective Morita-BaylisHillman reactions of aromatic aldehydes with methyl vinyl ketone. Tetrahedron Lett. 2008, 49, 6262-6264. [CrossRef]

40. Berkessel, A.; Roland, K.; Neudörfl, J.M. Asymmetric morita-baylis-hillman reaction catalyzed by isophoronediamine-derived bis(thio)urea organocatalysts. Org. Lett. 2006, 8, 4195-4198. [CrossRef] [PubMed]

41. Shi, M.; Liu, X. Asymmetric Morita-Baylis-Hillman Reaction of Arylaldehydes with 2-Cyclohexen-1-one Catalyzed by Chiral Bis(Thio)urea and DABCO. Org. Lett. 2008, 10, 1043-1046. [CrossRef]

42. Krishna, P.R.; Kannan, V.; Reddy, P.V.N. N-Methylprolinol Catalysed Asymmetric Baylis-Hillman Reaction. Adv. Synth. Catal. 2004, 346, 603-606. [CrossRef] 